\title{
Effect of the Nozzle-Substrate Distance on the Structural and Optical Properties of ZnO Thin Films Deposited by Spray Pyrolysis Technique
}

\author{
Abdelkader Hafdallah ${ }^{1,2, *}$, Abderrahman Azzedine ${ }^{1}$, Hanane Belhani ${ }^{1}$, Mohamed Salah Aida ${ }^{2}$, \\ Nadhir Attaf ${ }^{2}$ \\ ${ }^{1}$ LPAT, Department of Material Sciences, Faculty of SESNV, University of Tebessa, Tebessa, Algéria \\ ${ }^{2}$ LCMI, Department of Physics, Faculty of Sciences, University of Constantine 1, Constantine, Algéria \\ Email address: \\ hafdallah@gmail.com (A. Hafdallah) \\ ${ }^{*}$ Corresponding author

\section{To cite this article:} \\ Abdelkader Hafdallah, Abderrahman Azzedine, Hanane Belhani, Mohamed Salah Aida, Nadhir Attaf. Effect of the Nozzle-Substrate \\ Distance on the Structural and Optical Properties of ZnO Thin Films Deposited by Spray Pyrolysis Technique. American Journal of Nano \\ Research and Applications. Vol. 5, No. 6, 2017, pp. 87-90. doi: 10.11648/j.nano.20170506.12
}

Received: October 18, 2017; Accepted: November 6, 2017; Published: December 18, 2017

\begin{abstract}
In the present work, zinc oxide ( $\mathrm{ZnO})$ thin films were deposited by pyrolysis spray technique on glass substrate temperature $350^{\circ} \mathrm{C}$, using the zinc acetate with a molarity of $0.1 \mathrm{M}$. Our interest is on the investigation of the nozzle-substrate distance on the structural and optical properties of the films. Structural analysis by X-ray diffraction showed that the deposited films have a preferred orientation along the direction (002) and are relatively uniform. The spectrophotometer UV-Visible confirms that it is possible to get good transparent $\mathrm{ZnO}$ films with a transmission of 80 to $95 \%$ in the visible. The values of optical gaps Eg deduced from the spectra of UV-Visible transmissions vary between 3.21 and $3.25 \mathrm{eV}$.
\end{abstract}

Keywords: ZnO, Thin Films, Nozzel-Substrate, Spray Pyrolysis, XRD, Optical Properties

\section{Introduction}

During these last decades, the thin films of zinc oxide $\mathrm{ZnO}$ aroused a great interest, like conducting transparent oxides. This is with the properties optical and electric zinc oxide, its thermal and chemical stability very high, it's no toxicity like its abundance in the nature more; it presents a gap of $3,3 \mathrm{eV}$ and an excitonic binding energy of $60 \mathrm{meV}$. These films were used in several electronic and optoelectronic fields such as: sensors with conducting gases [1], thermal barriers [2], the solar cells [3].

To improve zinc oxide $\mathrm{ZnO}$ properties, various growth techniques, including chemical vapor deposition [2], solgel method [2], electrochemical deposition [3], sputter deposition [4], hydrothermal technique [5] and spray pyrolysis technique (SPT) [6] have been employed to obtain pure zinc oxide $\mathrm{ZnO}$ thin films on various substrates. SPT in particular has attracted attention due to its versatility, scalability and the possibility to control the thickness of thin films and hence tailor them to specific applications. The economic viability of SPT derives from the advantage of inexpensive equipment (non-vacuum method), the ease of large area deposition and continuous fabrication by moving nozzle over a substrate.

In this article, thin films of $\mathrm{ZnO}$ were deposited by spray pyrolysis technique, starting from a zinc acetate solution, on heated substrates out of glass.

In this work, the effect of the nozzle-substrate distance on the structural and optical properties of $\mathrm{ZnO}$ films has been studied. Moreover, $\mathrm{ZnO}$ thin films were deposited by ultrasonic spray technique with a non aqueous starting solution. 


\section{Experimental}

The samples used in this study were deposited using a device made in the laboratory. The solutions used are zinc acetate $\left(\mathrm{C}_{4} \mathrm{H}_{6} \mathrm{O}_{4} \mathrm{Zn} .2 \mathrm{H}_{2} \mathrm{O}\right)$ dissolved in methanol. The spray liquid is then carried through a pyrolysis system that converts the into fine droplets. These precursors are ejected onto glass substrates placed below a substrate holder heated to a fixed temperature $350^{\circ} \mathrm{C}$.
Our focus is to study the effect of the nozzle-substrate distance on the structural and optical proprieties of these films.

The crystal structure of the $\mathrm{ZnO}$ thin film was determined by X-ray diffraction (XRD) using diffractometer with $\mathrm{CuK} \alpha$ $\mathrm{X}$-ray source. The optical transmission spectra are used to study the optical properties of deposit thin films and have been analyzed using UV-Visible spectrophotometer at room temperature.

Table 1. The experimental conditions for the deposited zinc oxide ( $\mathrm{ZnO}$ ) thin films.

\begin{tabular}{|c|c|c|c|c|}
\hline & Deposition time(min) & Nozzle-substrate distance $(\mathrm{cm})$ & Substrate temperature $\left({ }^{\circ} \mathrm{C}\right)$ & Solution concentration(M) \\
\hline Zinc acetate $\mathrm{C}_{4} \mathrm{H}_{6} \mathrm{O}_{4} \mathrm{Zn} .2 \mathrm{H}_{2} \mathrm{O}$ & 5 & $15,20,25$ and 30 & 350 & 0.1 \\
\hline
\end{tabular}

\section{Results and Discussion}

Figure 1 shows the variation of the growth rate as a function of the nozzle-substrate distance. The growth rate is estimated from the ratio of film thickness on the deposition time fixed at $5 \mathrm{~min}$.

In this figure in that the growth rate decreases with the nozzle-substrate distance, this decrease being due to the number of the droplets to be evacuated on the heated substrate because the kinetic energy of large size droplets are with a great inersity [8].

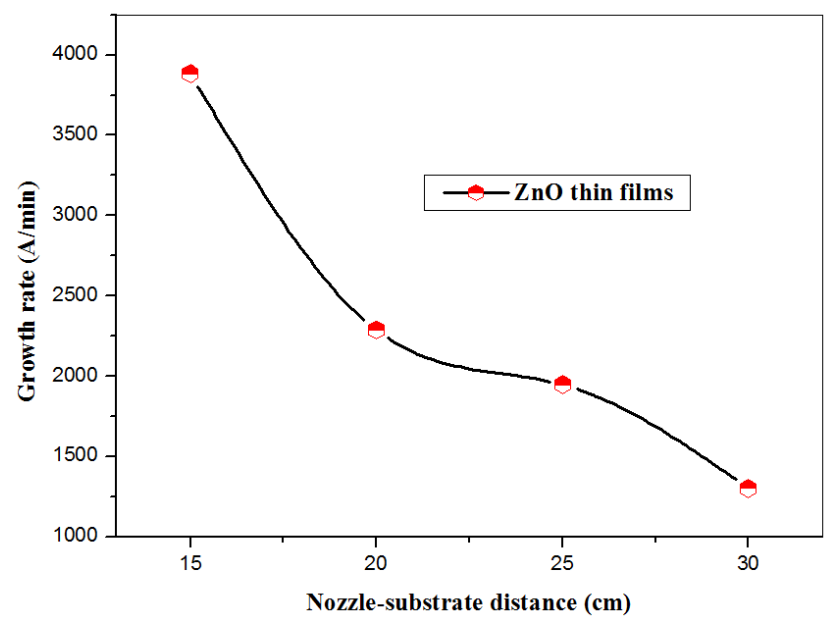

Figure 1. Variation of growth rate with nozzle-substrate distance.

Figure 2 shows the XRD patterns of zinc oxide $\mathrm{ZnO}$ films with different nozzle-substrate distance. As seen from this figure, the films exhibit a dominant peak at $2 \Theta=34.34^{\circ}$ corresponding to the (002) plane of zinc oxide $\mathrm{ZnO}$ [9]. Other peaks corresponding to (100) and (101) plans are also present in the spectra indicating the polycrystalline nature of the obtained films. Note also a decrease of the peaks (001) and (101) in the 20 and $25 \mathrm{~cm}$ layers and the absence totally in the $30 \mathrm{~cm}$ layer this phenomenon interpreted by the number of droplets incident on the heated substrate and confirmed by the growth rate [10].

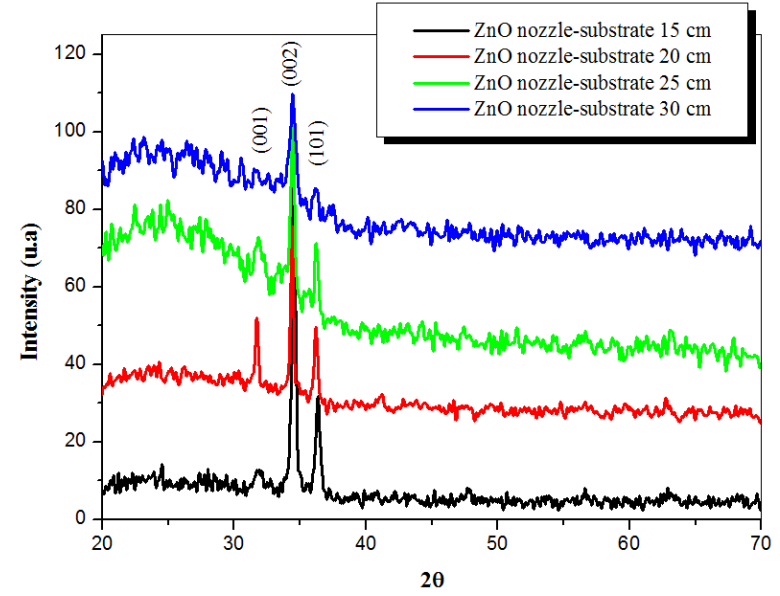

Figure 2. XRD patterns of $\mathrm{ZnO}$ films prepared with different nozzlesubstrate distance.

The grain size of crystallites was calculated using a wellknown Scherrer's formula [11]:

$$
\mathrm{D}=0.9 \lambda / \beta \cos \Theta
$$

Where $\mathrm{D}$ is the grain size of crystallite, $(\lambda=1.54059 \AA)$ the wavelength of $x$-rays used, $\beta$ the broadening of diffraction line measured at half its maximum intensity in radians and $\theta$ the angle of diffraction.

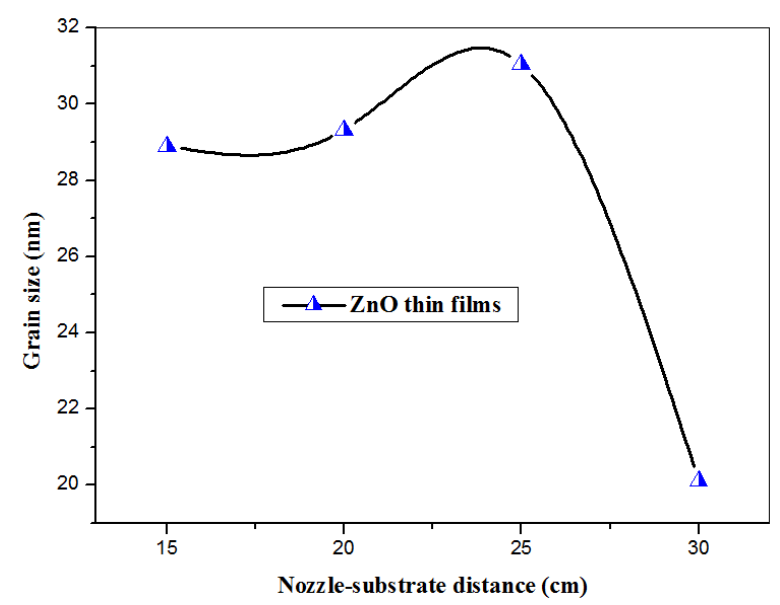

Figure 3. Variation of grain size with nozzle-substrate distance. 
The variation of grain size with nozzle-substrate distance for these films is presented in the figure 3. In this figure, a slight increase in the grain size between 29 and $31 \mathrm{~nm}$, this increase due to the improvement in the crystallinity of the films 15,20 and $25 \mathrm{~cm}$ and then a decrease of up to $20 \mathrm{~nm}$ corresponds to the grain $30 \mathrm{~cm}$ and this decrease interpreted by the absence of the peaks (001) and (101) and all confirmed by the spectra of XRD [10].

Figure 4 shows the optical transmission spectra recorded in the range from 300 to $1100 \mathrm{~nm}$ obtained in films prepared with different nozzle-substrate distance. As can be seen, a region of strong transparency is located between 400 and $1100 \mathrm{~nm}$. The value of the transmission is about $75-90 \%$. In this wavelength range we have also observed interference fringes. These fringes are due to the multiple reflections on the two interfaces of the film. This indicates that the films prepared with these conditions are smooth and uniform [12]. In addition, a strong absorption region, which corresponds to the fundamental absorption due to the inter-band electronic transition, is seen in the higher photon energy region [10].

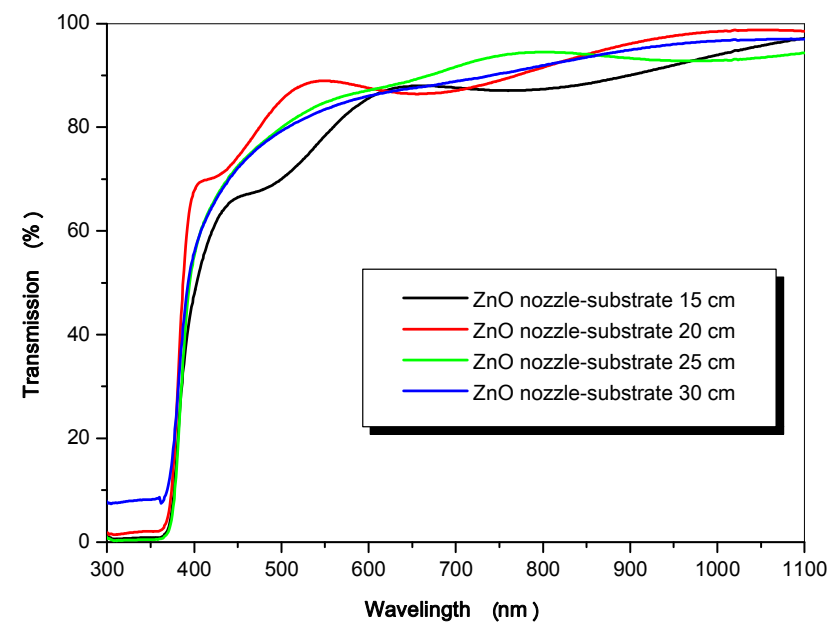

Figure 4. Optical transmittance of $\mathrm{ZnO}$ films at nozzle-substrate distance.

In figure 5 we observe what are called localized states formed in band tails at the boundaries of the bandgap in the valence and conduction band. For energies greater than Ec and less than Ev, the extended states are found (Figure 5), this difference is known as disorder. When the disorder becomes too great (eg with the appearance of hanging bonds or impurities in the material), the tails may become entangled. We will then define the notion of Urbach parameter $\left(\mathrm{E}_{00}\right)$ which corresponds to transitions between the extended states of the valence band and the localized states of the conduction band. The absorption coefficient is linked to disorder by the law [13]:

$$
\alpha=\alpha_{0} \exp \left(\mathrm{hv} / \mathrm{E}_{00}\right)
$$

$\mathrm{E}_{00}$ being the width of the tape tail that characterizes the disorder.

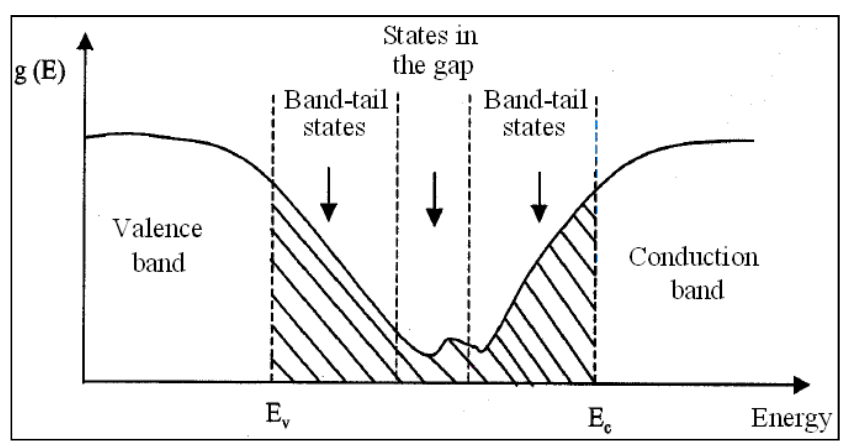

Figure 5. Function of distribution of the energy states in the bands.

Figure 6 shows the variation of the disorder (Urbach energy) as a function of nozzle-substrate distance of $\mathrm{ZnO}$ thin films.

A decrease of disorder (Urbach energy) at the distance less $25 \mathrm{~cm}(5$ to $25 \mathrm{~cm})$, because this distance allows the atoms find a good site that is to say a better organization of the $\mathrm{ZnO}$ film, ie layers become homogeneous and well crystallized.

An increase in disorder (Urbach energy) for the distance greater than $25 \mathrm{~cm}$ because this distance does not allow the atoms arriving on the substrate surface to find a good favourable site (the random deposited atoms on the surface) [14].

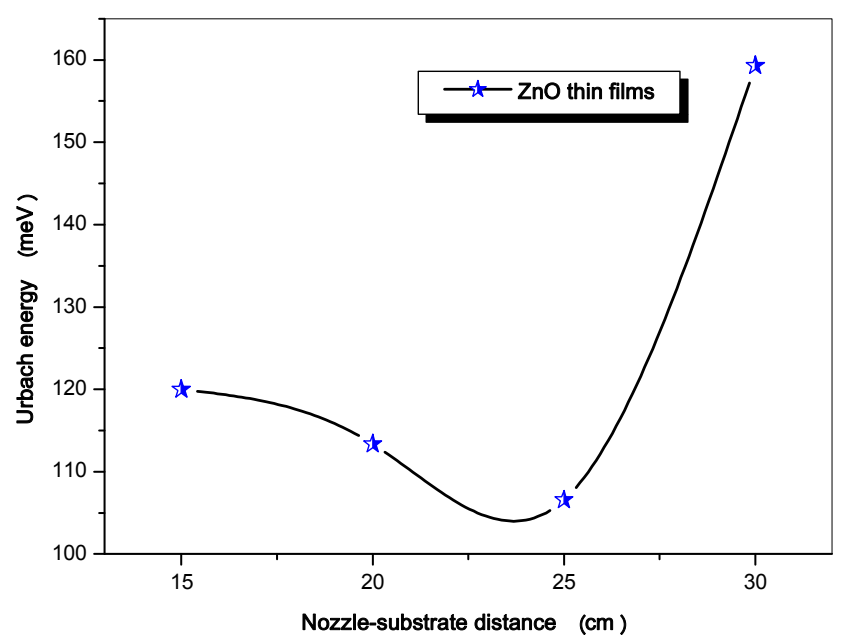

Figure 6. Variation of Urbach energy with nozzle-substrate distance.

The optical band-gaps of the zinc oxide thin films $(\mathrm{ZnO})$ had been calculated using equation

$$
(\alpha h v)=A(h v-E g)^{m}
$$

The optical band gap was obtained by plotting $(\alpha h v)^{2}$ as a function of photon energy (hv). The intercept of the extrapolation to zero absorption with photon energy axis gave the values of the direct energy gap Eg [11].

The variation of the deduced optical gap of films with nozzle-substrate distance is reported in figure 7.

The optical gap is defined as the minimum energy to excite an electron from the valence band to the conduction band. In pure non-doped crystals the optical gap equals the energy separation between the band edges (BV and BC) [15]. 
The band gap values in our zinc oxide $\mathrm{ZnO}$ films are between 3.21 and $3.26 \mathrm{eV}$.

Note that the optical band gap increases with increasing nozzle-substrate distance for the distance less than $25 \mathrm{~cm}$, and after the distance of $30 \mathrm{~cm}$ we observe an optical gap which decreases to $3.21 \mathrm{eV}$, This decrease due to the increase in optical disorder (Urbach energy).

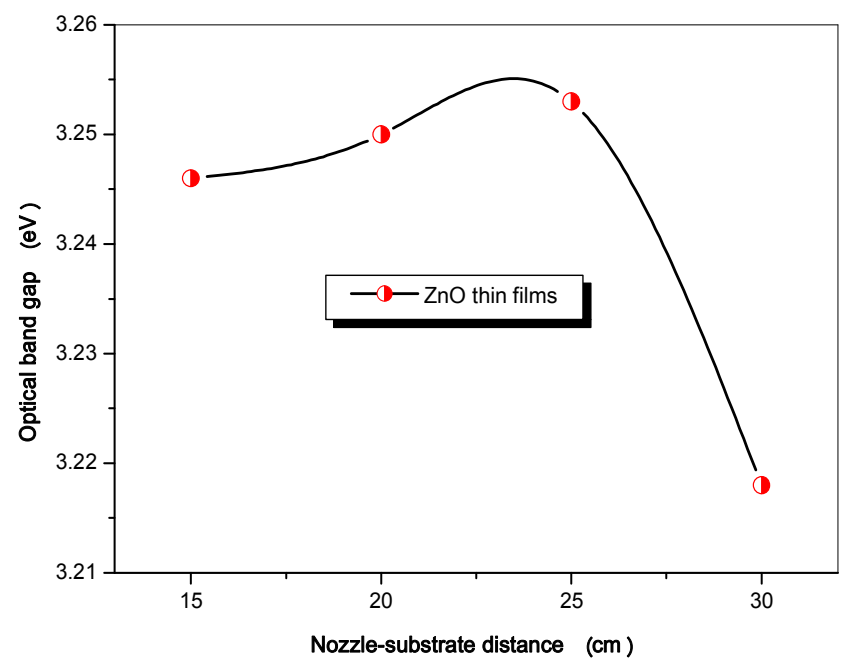

Figure 7. Variation of the optical band gap as a function of the nozzlesubstrate distance.

As seen (Figure 5, 6 and 7), the variations of both Eg and Eu correlate very well. This effect indicates that the optical gap variation is mainly controlled by the disorder in the film. The increasing of the nozzle-substrate distance $(15 \mathrm{~cm}$ to $25 \mathrm{~cm}$ ) can improve the organization and the crystallinity of films (decrease of the disorder (urbach energy)), and therefore improves the optical transmission of the films (increasing of optical gap). The best transparency of $\mathrm{ZnO}$ thin films deposited by spray pyrolysis is obtained at the nozzle-substrate distance $25 \mathrm{~cm}$ (less of disorder).

\section{Conclusion}

Zinc oxide $(\mathrm{ZnO})$ thin films were deposited by pyrolysis spray technique with a non aqueous solution. The effect of nozzle-substrate distance on the structural and optical properties of films was investigated. The crystallinity all films is improved with nozzle-substrate distance. $\mathrm{ZnO}$ films preserve their (002) preferential orientation. The optical characterization on a broad range of 300 to $1100 \mathrm{~nm}$ showed that films have a stronge transmission of about 80 to $95 \%$. The obtained optical gap values for the different nozzle- substrate distances are in good agreement with the data of literature $(3.2 \sim 3.3 \mathrm{eV})$.

\section{References}

[1] Abdelkader HAFDALLAH, Abdelhamid FERDI, Mohamed Salah AIDA, Nadhir ATTAF and Abdelaziz Amara, International Journal of Advanced Research, Volume 3, (2015), 240-246.

[2] Abdelkader HAFDALLAH, Khaoula DERRAR, Mohamed Salah AIDA et Nadhir ATTAF, Afrique SCIENCE 12(3) (2016) 26-33.

[3] Prabakaran Kandasamy and Amalraj Loudusamy, International Journal of Physical Sciences, vol. 9, no11, (2009) 261-266.

[4] S. Zargou, S. M. Chabane Sari, A. R. Senoudi, M. Aida, N. Attaf, I. F. Hakem. J. Mater. Environ. Sci. 7(9)(2016) 31343147.

[5] C. S. Prajapati, A. Kushwaha, P. P Sahay. Mat. Chem. And Phys. 142 (2013) 276.

[6] N. Lehrakia, M. S. Aida, S. Abed, N. Attaf, A. Attaf, M. Poulain. Current Applied Physics 12 (2012) 1283-1287S.

[7] Bhavana Godbole, Nitu Badera, Shyambihari Shrivastava, Deepti Jain, Vganesan Ganesan, Materials Science and Applications,2 (2011) 643-648.

[8] HAFDALLAH Abdelkader, YNINEB Fayssal, DARANFED Warda, ATTAF Nadhir et AIDA Mohamed Salah, Revue «Nature \& Technologie».n06/Janvier (2012) Pages 25 à 27.

[9] R. Ayouchi, F. Martin, D. Lienen, J. R. Ramos-Barrado, Journal of Cristal Growth, 247 (2003) 497-504.

[10] Yacine Aoun, Boubaker Benhaoua, Said Benramache, Brahim Gasmi. Optik 126 (2015) 5407-5411.

[11] A. Hafdallah, F. Ynineb, M. S. Aida and N. Attaf, Journal of Alloys and Compounds 509 (2011) 7267-7270.

[12] M. Saleem, L. Fang, H. B. Ruan, F. Wu, Q. L. Huang, C. L. $\mathrm{Xu}$ and $\mathrm{C}$. Y. Kong. International Journal of Physical Sciences Vol. 7 (23) (2012) 2971-2979.

[13] F. Ynineb, A. Hafdallah, M. S. Aida, N. Attaf, J. Bougdira, H. Rinnert, S. Rahmane, Materials Science in Semiconductor Processing, 16 (2013) 2021-2027.

[14] G. Anil Kumar, M. V. Ramana Reddy and Katta Narasimha Reddy. Research Journal of Physical Sciences. 1(6) (2013) 17-23.

[15] Atheer Ibraheem Abd Ali. International Journal of Scientific \& Engineering Research, Volume 5, Issue 1, (2014). 